\title{
Narrativas Guaranis de José de Melo e Silva (1939) na Fronteira Brasil/Paraguai
}

\author{
Narrativas Guaraníes de José de Melo e Silva (1939) en la Frontera \\ Brasil/Paraguay
}

Guarani Narratives of José de Melo e Silva (1939) on the Brazil / Paraguay Frontier

\author{
Ms. Wagner Henrique Neres Fiuza ${ }^{1}$ \\ Dra. Beatriz Anselmo Olinto
}

\begin{abstract}
Resumo
Neste trabalho, entende-se que a produção de conhecimento veiculada por meio de textos e autores foi um alicerce de expansão do modelo de estado nacional brasileiro denominado Estado Novo (1937-1945). Tal produção visava estabelecer limites de atuação do estado, legitimando uma política de valorização do nacional em relação ao elemento estrangeiro. Neste contexto, o trabalho objetiva discutir a visão do outro no texto Fronteiras Guaranis (1939), obra de José de Melo e Silva, à época profundamente engajado com o projeto político de Getúlio Vargas denominado Marcha para Oeste. Em seu trabalho, Melo e Silva constrói a brasilidade em oposição ao "guaranizado" paraguaio, elemento fronteiriço que estaria ameaçando culturalmente a fronteira brasileira. $\mathrm{O}$ autor trabalha argumentos eugênicos para caracterizar aquela população, condicionando suas ações por sua etnia, e propondo soluções para integrar aquelas pessoas ao que chamava de civilização brasileira. Entende-se que ao buscar narrar uma história e constituir uma geografia humana na fronteira, Melo e Silva instituiu identidades, (re)criando aquele espaço e com isso delimitando os lugares sociais que deveriam ser ocupados pelos indígenas paraguaios, no geral como mão-de-obra barata para a extração da erva-mate e o treinamento para o trabalho agrícola em escolas profissionais. Tais ideias integram elementos materiais e imateriais do discurso, demarcam e legitimam projetos políticos e processos de classificação e controle estatal de povos indígenas em prol de um modelo de sociedade baseado na agropecuária.
\end{abstract}

Palavras-Chave: José de Melo e Silva, Fronteiras Guaranis, Mato Grosso do Sul, Guaranis, Paraguai.

\section{Resumen}

En este trabajo, se entiende que la producción de conocimientos transmitidos a través de textos y autores era una expansión del modelo de Estado nacional brasileño llamado Estado Novo (1937-1945). Dicha producción tuvo como propósito establecer límites de actuación estatales, con el fin de legitimar una política nacional de valoración frente el extranjero. En este contexto, el trabajo analiza la vista del otro en el texto Fronteiras Guaranís (1939), la obra de José de Melo e Silva, en el momento profundamente comprometido con el proyecto político de Getúlio Vargas llamado Marcha para Oeste. En su trabajo, Melo y Silva construye brasilidad en contraposición a "guaranizado", el elemento de frontera con Paraguay que estaría culturalmente amenazando la frontera con Brasil. El autor trabaja argumentos eugenésicos para caracterizar esa población, el acondicionamiento de sus acciones por su origen étnico, y proponer soluciones para integrar a las personas a lo que llamó la civilización brasileña. Se entiende que en la búsqueda de narrar una historia y una geografía humana en la frontera, Melo y Silva establecieron las identidades, (re)crear el espacio y delimitando así los

\footnotetext{
${ }^{1}$ Mestre em História e Regiões; Secretaria Estadual de Educação do Paraná (SEED), Guarapuava, Paraná, Brasil; wagnerunicentro@ hotmail.com. Trabalho apresentado no I Seminário Latino-Americano de Estudos em Cultura - SEMLACult, Foz do Iguaçu/PR, Brasil, 2017.

${ }^{2}$ Doutora; Professora Associado no Departamento de História da UNICENTRO; Guarapuava, Paraná, Brasil; biaolinto@hotmail.com
} 
lugares sociales que deben ser ocupados por los indios paraguayos en general como mano de obra baratas para el extracto de yerba mate y la formación para el trabajo agrícola en las escuelas profesionales. Tales ideas se integran elementos tangibles e intangibles de expresión, demarcar y proyectos políticos y los procesos de clasificación y control del estado de las poblaciones indígenas hacia un modelo de sociedad basado en la legitimación de la agropecuária.

Palabras claves: José de Melo e Silva, Fronterias Guaranís, Mato Grosso del Sul, Guaranis, Paraguay.

\begin{abstract}
In this paper, it is understood that the production of knowledge transmitted through texts and authors was an expansion of the Brazilian national state model called Estado Novo (1937-1945). The purpose of this production was to establish state limits of action, in order to legitimize a national policy of valuation against foreigners. In this context, the paper analyzes the view of the other in the text Fronteiras Guaranis (1939), the work of José de Melo e Silva, at the time deeply committed to the political project of Getúlio Vargas called March for the West. In his work, Melo y Silva builds Brazilians as opposed to "Guarani", the border element with Paraguay that would be culturally threatening the border with Brazil. The author works eugenic arguments to characterize this population, the conditioning of their actions by their ethnic origin, and propose solutions to integrate the people to what he called the Brazilian civilization. It is understood that in the search to narrate a history and a human geography in the border, Melo and Silva established the identities, (re) to create the space and delimiting thus the social places that must be occupied by the Paraguayan Indians in general like hand of Cheap labor for yerba mate extract and training for agricultural work in professional schools. Such ideas integrate tangible and intangible elements of expression, demarcation and political projects and the processes of classification and control of the state of indigenous populations towards a model of society based on the legitimacy of agriculture.
\end{abstract}

Key words: José de Melo e Silva, Guaraní Frontier, Mato Grosso do Sul, Guaranis, Paraguay.

\title{
1. Introdução
}

Em meados da década de 1930, o Brasil passou por um processo de expansão estatal e de novas políticas culturais, cuja forma final foi o Estado Novo (1937-1945), e que diziam respeito a uma via de mão dupla: o controle estatal sobre a produção artística e intelectual por meio de órgãos e departamentos estatais de censura, aliada a uma política cultural em que "poucos intelectuais conseguem resistir aos apelos de integração por parte do Estado (VELLOSO, 1987, p. 45). Foi neste mesmo ambiente que houve um estímulo para que a nação brasileira voltasse seus olhos para o oeste, oferecendo a presença do Estado como garantia dos princípios fundamentais que o regiam, como a propriedade privada e a segurança nacional. Ocupar o oeste era pensado como tomar para si aquilo que lhe era de direito. Contudo, a historiografia demonstra que os projetos políticos de ocupação a oeste no Brasil, tanto em nível nacional quanto regional, foram processos de (re)ocupação e territorialização de instituições e poderes, utilizando a cartografia como representação de um espaço conhecido, logo, dominado (FREITAG, 2007, p. 70).

No primeiro quarto de século brasileiro, o oeste esteve associado ao atraso, ambiente selvagem, chamado sertão (MACHADO, 2012, p. 65). A crença de que o meio faz o homem possibilitava distintas interpretações: o homem forte, calejado pelas dificuldades e que vencia a natureza; e aquele homem engolido pelo seu ambiente, primitivo e distante da vida urbana e 
civilizada, e invariavelmente, doente. O oeste pertencia foi tomado, portanto, como terra de ninguém, uma verdadeira fronteira aberta (MACHADO, 2012, p. 25-35). Conhecê-lo foi entendido como uma necessidade proveniente dos centros de poder brasileiro, localizados grosso modo no litoral, que formularam discursos e projetos para o avanço da nação brasileira, o que incluía cartografá-lo, saneá-lo, medicá-lo. No âmbito dessa rede discursiva, era neste oeste selvagem, ameaçador, que se encontravam os povos indígenas, brasileiros que não sabiam de sua própria condição de brasilidade. Caberia, portanto, ao Estado fazer valer esta identidade àqueles povos. O movimento de levar pressupostos de civilização para oeste foi recebido nestes lugares, inclusive com intelectuais do outro lado aderindo à ideia de integrar os eixos leste-oeste do país (CALONGA, 2015, p. 127). Dentre eles, está José de Melo e Silva, juiz de direito que atuou na fronteira Brasil/Paraguai durante a década de 1930.

Segundo Seth Garfield, entre diversas expedições de reconhecimento e demarcação dos limites na fronteira oeste brasileira, houve destaque para um movimento específico denominado Marcha para Oeste, e cuja mobilização estatal e midiática para comunica-lo à sociedade pode ser entendido enquanto um espetáculo da encenação pública do período (GARFIELD, 2011, p. 48). Ao aderir ao apelo de integração nacional do Estado, Melo e Silva buscou intervir com argumentos de quem já estava no oeste, e de lá acompanhou esse movimento: "Que venham, portanto, os brasileiros de outros recantos para se fixarem naquele solo. Até certo ponto será isso uma elevada missão, de cunho profundamente patriótico" (MELO E SILVA, 2003, p. 185).

Mas, que tipo de Brasil era esperado para aquela fronteira e quais suas implicações para as populações indígenas que lá habitavam? Assim, a pesquisa problematiza o texto de José de Melo e Silva, autor engajado com o Estado Novo e a política da Marcha para Oeste. Suas ideias, partícipes de um discurso jurídico e de uma discussão eugênica, remontam à narrativas de fronteiras acerca dos guaranis paraguaios, ou dos "guaranizados", como Melo e Silva os chamava.

\section{Fronteiras Guaranis}

O texto Fronteiras Guaranis (1939) traz narrativas sobre a presença dos guaranis na fronteira meridional de Mato Grosso. Seu autor, José de Melo e Silva, utilizou seu cotidiano de trabalho como juiz de direito, que lhe permitia viajar pelos municípios daquela fronteira, para escrever e fotografar informações sobre aquelas populações fronteiriças. Do texto, retiramos alguns excertos para pensar que tipo de guarani foi cristalizado naquela obra, e 
quais as implicações destas práticas de escrever se propagarem no tempo e no espaço emitindo juízos sobre pessoas, demarcando lugares, identidades e delimitando regiões.

Atento à política governamental de sua época, Melo e Silva relatou iniciativas de contato com comunidades indígenas “isoladas". O autor é elogioso tanto ao Serviço de Proteção ao Índio (SPI), realizador do que chamou de "visitas carinhosas", quanto a militares como Cândido Rondon e o Capitão Daniel Lopes (MELO E SILVA, 2003, p. 76). Para ele, as notícias de tais contatos demonstravam que os índios Caiuás, que ficavam do lado brasileiro, "falam o guarani e são mais ou menos civilizados" (MELO E SILVA, 2003, p. 75), ou seja, estavam num estágio de quase-civilização que permitiria integrá-los até mesmo com o fornecimento de terras. Já na fronteira, miscigenado com o castelhano, o guarani paraguaio conservava um “idioma primitivo adulterado, que geralmente é usado para identificá-los" (MELO E SILVA, 2003, p. 81).

Nessa avaliação, estabelece-se elementos de diferenciação entre os guaranis paraguaios e os caiuás brasileiros, sendo que o objeto privilegiado do autor foram os indígenas considerados estrangeiros. Reclamou, por exemplo, que naquele espaço fronteiriço o elemento trabalhador era rarefeito, o que causava efeitos como "salários são exagerados e o braço improdutivo" (MELO E SILVA, 2003, p. 99). Para ele, aquela fronteira era refém da economia da erva-mate, e por isso, registrou indignado que o guarani paraguaio, "sendo um operário de grande resistência e capacidade, qualidade que denota nos primeiros dias de trabalho, torna-se imprestável, em via de regra, depois de pouco tempo" (MELO E SILVA, 2003, p. 99). Ressalta-se que Melo e Silva opera sua narrativa sobre a contradição, apresentando aquele operário como resistente e capaz, mas também descontínuo, irregular. Para ele, trabalho e trabalhador estavam ligados à escala de civilização de uma sociedade e a agricultura representava melhor o trabalho civilizado do que os ervais. Por isso, Melo e Silva dizia abundar operários guaranis, mas reclamava da falta de trabalhadores.

Além do trabalho, o jurista também se preocupava com o desrespeito às fronteiras internacionais, que deveriam ser fixadas na terra e acompanhadas de um aparato jurídico político que as definisse e fizesse respeitar. Contra essa definição, listou a facilidade dos guaranis paraguaios em transpor a fronteira, sob uma condição de "nomadismo moderno", pois, "penetrando no solo brasileiro", constituem uma "parte considerável, embora um tanto flutuante da nossa população" (MELO E SILVA, 2003, p. 81). Por nômades e flutuantes Melo e Silva entende populações que não se fixam, e que tornam a fronteira porosa e permeável, o contrário do que deveriam ser, e distantes do conceito de civilização do autor. 
Tal presença estaria afetando a própria estrutura da família, condição sine qua non da brasilidade. Para ele, a não ser que a mãe fosse brasileira, os filhos nascidos no Brasil não se adaptavam facilmente à nossa educação. Isso seria uma resistência do "matriarcado indígena primitivo", outro elemento inferior de uma civilização governada por mulheres, que não cumpriam suas funções na sociedade moderna como ser mãe e cuidar da casa, numa acepção conservadora e machista de família cristã presente nos textos do autor. Essas famílias "mestiças" contribuíam para deturpar a língua brasileira, pois os "brasileiros mestiços" só entendiam se "falar em seu nível de vocabulário"; e até os não-mestiços utilizavam termos castelhanos no dia a dia, constituindo péssimo exemplo para os filhos e uma indiferença à “pureza da língua brasileira” (MELO E SILVA, 2003, p. 82).

Para ele, a mestiçagem no sangue constituiria um caráter malicioso do guarani fronteiriço. Da experiência do autor como juiz de direito, citou que em testemunhos de um "mestiço" à justiça, via de regra não havia colaboração com a verdade. A carga da mentira e da falta de honra recai sobretudo em relação ao guarani paraguaio, chegando a citar que nos casos mais sérios "só a coação física poderia modifica-lo" (MELO E SILVA, 2003, p. 84). Não podemos perder de vistas que estas definições de Melo e Silva não correspondem ao que aqueles guaranis eram de fato, mas sim a representações que demarcam um lugar simbólico para aquelas populações. Falar daqueles outros significava estabelecer uma oposição baseada em "nós brasileiros", utilizando para isso relações de poder estabelecidas nas instituições como a Justiça ou no cotidiano do falar. Definir as "imperfeições" daqueles guaranis era, na verdade, um ato para demarcar o que significava ser brasileiro, ou melhor, qual deveria ser o Brasil a ser vivido naquele lugar.

Como já dito, esta narrativa não é rígida, mas sim baseada em levantar contradições, ressaltando pontos positivos e negativos daquelas pessoas dentro dos ideais de nação estabelecidos pelo narrador. Destacou, por exemplo, que o guarani paraguaio tem "seu gênio alegre" que "empresta uma feição original aos seus costumes", contudo "A maior parte do seu tempo se escoa em diversões - danças, passeios e musicatas" (MELO E SILVA, 2003, p. 84). Melo e Silva, apesar de destacar personalidades alegres e musicais, lamentava que isso se tornasse em horas desperdiçadas bebendo e cantando, ou em casas de comércio testando instrumentos, procurando fugir de um trabalho contínuo e disciplinado. Além da pureza da língua, a ojeriza pelo trabalho e a assimilação de certos costumes brasileiros como o carnaval contribuía para criar na fronteira um "império da ociosidade" (MELO E SILVA, 2003, p. 84).

Assim, tal qual inúmeros outros textos da década de 1930, Fronteiras Guaranis (1939) estabelece uma relação com os grupos guaranis intermediada por outros estudos anteriores, 
considerados científicos, como de Sigmund Freud ou Nina Rodrigues. Neste sentido, o texto ocupou espaços nos discursos da ciência e da medicina, modelos de classificação e hierarquização da sociedade na década de 1930. Porta-voz autorizado dos códigos culturais e discursos expressos como verdade em seu tempo, Melo e Silva subjugou pela linguagem e cristalizou escalas de civilização para os guaranis da fronteira. Porém, sua narrativa caracteriza-se por um jogo constante entre ciência e religião, que aparecem como alicerces sólidos para sua "plataforma de fronteira" (CENTENO, 2007, p. 175). Naquele texto, tanto a medicina quanto a espiritualidade guarani, eram explicáveis e corrigíveis, sob as chaves de leitura da ciência e do catolicismo associadas à ação da mão forte do Estado.

Este é um ponto importante. A escrita de Melo e Silva é lógica, ou seja, busca construir argumentos baseados na experiência de quem testemunha a fronteira, aliada a estudos científicos submetidos àquele objeto, de modo que as conclusões sejam irrefutáveis pelo leitor, e logicamente aceitas. Assim, os guaranis são descritos como portadores de uma vida sexual desvairada e promíscua, que desvirtuava o que havia de bom nos "valores primitivos da raça". Mas essa é a visão construída pela escrita de um homem, católico, conservador, fiduciário do regime de propriedade privada e do matrimônio como ordem social dos bens imobiliários e heranças, além de valor moral na vida pública e privada, e que buscava restaurar certos princípios idealizados e resgatar valores considerados perdidos.

Neste sentido, pode-se dizer que o texto Fronteiras Guaranis (1939) atuou para "impor a definição legítima das divisões do mundo social e, por este meio, de fazer e de desfazer os grupos" (BOURDIEU, 2010, p. 113). Ao valorar determinado tipo de trabalho em detrimento de outro, ou ainda, esquadrinhar estas demarcações do espaço geográfico e cultural de uma comunidade imaginada, nos termos de Benedict Anderson, projetando-a sobre outros grupos, o texto di-vidiu o mundo social daquela fronteira entre eles, os outros guaranis paraguaios ou os outros mestiços, e o nós, os brasileiros, utilizando como base textos e metodologias que homogeneizavam autores sob a alcunha de ciência.

Em seu ímpeto científico, Melo e Silva se perguntou: por que existiria tanta diferença entre os guaranis paraguaios e os guaranis retratados por autores e expedições brasileiras? Para responder esta questão, Melo e Silva se apropriou de algumas das discussões de raça, comuns no século XIX brasileiro, como a influência do meio na formação do homem, continuadas no século XX sob nova roupagem, como a expansão dos discursos de higienização da sociedade sob o viés da genética e da hereditariedade, geralmente agrupados sob a ideia de eugenia. Assim, em um longo rodapé, o autor questiona: Se no início havia um só povo tupi-guarani, de notável civilização, de onde vêm esses costumes fronteiriços que não 
pertencem aos guaranis puros? A primeira hipótese é de que essas marcas seriam provenientes da mistura com o elemento espanhol de baixa procedência (MELO E SILVA, 2003, p. 86-87). Mas, Melo e Silva buscou ainda uma outra explicação anterior, na diferença estabelecida por Moisés Bertoni entre guaranis e guaranizados (MELO E SILVA, 2003, p. 117-118).

Embora tenha polemizado com Bertoni durante toda a primeira parte do texto, neste momento Melo e Silva buscou amparo nas conclusões dele para explicar o elemento humano da fronteira: "Se vivo e ouvido, o doutor Moisés Bertoni diria que estes fatos não ocorrem entre os guaranis e sim entre os guaranizados". O autor explica que "Bertoni estabeleceu uma distinção entre guaranis puros e guaranizados, resultando dessa diferenciação que só os últimos tem qualidades negativas, defeitos e vícios” (MELO E SILVA, 2003, p. 117).

Segundo Melo e Silva, haveria coincidência geográfica entre o argumento de Bertoni e as suas observações, afinal, "pondera ele que os indígenas do norte do Paraguai (precisamente os troncos de onde se originam estes que chamamos guaranis, na fronteira mato-grossense), não são guaranis", mas sim "povos que se guaranizaram. São os caainguás, estudados por Rengger, guaiquis, guaianás, arés e caiuás ou tamoios diz ele”. Ou seja, Bertoni dizia que aqueles paraguaios daquela fronteira sul do Mato Grosso "são guaranis apenas de língua, mas não de raça. Gente que conviveu longamente com os guaranis, não assimilando a sua cultura" (MELO E SILVA, 2003, p. 117).

Cabe ressaltar que essa explicação poderia ser considerada científica e legítima de explicar aquela fronteira na década de 1930. Em sua análise, também ressaltou que "segundo Bertoni, numerosas tribos que falavam a mesma língua e que deram origem a esses povos, que ele chama de guaranizados, eram hordas errantes insubmissas, sem as características diferenciais dos guaranis legítimos" (MELO E SILVA, 2003, p. 118). Ela seria, inclusive, pertinente para legitimar a superioridade indígena brasileira aos guaranizados paraguaios. Estes, que tanto causavam desordens na brasilidade fronteiriça, seriam de raça inferior desde tempos imemoriais, e o que se verificava era uma continuidade no presente. Urgia, portanto, modificar aquela situação.

Qual seria então o elemento ideal para aquele espaço? Para solucionar tal questão, Melo e Silva indica uma resposta possível: refere-se aos nordestinos como indício de uma possível experiência de cruza mendeliana de sucesso no Brasil (MELO E SILVA, 2003, p. 186-187, grifo nosso). Deste modo, o nordestino seria o exemplo de caracteres sanguíneos de diferentes raças que resultaram em um tipo novo com as melhores características genéticas do progenitor e do recessivo. Esta é uma das matrizes de pensamento da eugenia, muito difundido entre intelectuais brasileiros na primeira metade do século XX, e que foi baseada na 
retomada das teorias da hereditariedade de Gregor Mendel (1822-1844). No caso do Brasil, tanto o mendelismo quanto o neolamarckismo, uma referência aos trabalhos do francês Jean Lamarck (1844-1829), possuíram interlocutores que procuravam entender o Brasil e os brasileiros enquanto raça e nação.

Segundo Nancy Stephan, a herança neolamarckista positiva vislumbrava a transformação da raça pelo meio, sendo que ao melhorar o meio era possível melhorar a raça, e por isso se mostrou como alternativa para pensar o Brasil em propostas de reformas educacionais e assistência social. Já o mendelismo, cujas ideias diziam respeito à transmissão de genes pela combinação genética de características hereditárias impressas no sangue, sem influência do meio, teve presença significativa mas de menor abrangência entre os intelectuais brasileiros (STEPHAN, 2004, p. 380). Dentre estas formulações eugênicas sobre raça desenvolvidas no primeiro quarto de século no Brasil, baseadas tanto em uma herança mendeliana quanto neolamarckista, é possível dizer que ambas surgem concomitantes no texto de Melo e Silva, nos seus registros sobre o nordestino e sobre a fronteira guarani.

Mas, por quê uma cruza mendeliana de sucesso? Melo e Silva aponta que os guaranis puros são "elementos que se encontram hoje em perfeita fusão com os nossos povos, sem prejuízo de que muito se hajam conservado em um estado de pureza, em vida livre, isolada, e que por isso mesmo não experimentaram o processo de reversão ou cruzamento mendeliano (MELO E SILVA, 2003, p. 118). Estes guaranis estariam presentes em estados como Piauí, Maranhão, Pará e, especialmente o Ceará. Contudo, é da fusão desses guaranis puros os colonizadores, que indicariam uma cruza mendeliana notável, do qual emergiu o sertanejo nordestino. De tal cruza teria resultado características notáveis, por um lado o excelente agricultor que resiste à seca e as intempéries da natureza, pelo sangue europeu, e por outras qualidades como a hospitalidade presente em ambos os tipos, e que preponderou na fusão entre os elementos (MELO E SILVA, 2003, p. 187). Diferente, portanto, do caso de miscigenação na fronteira.

Para Melo e Silva, levar nordestinos para a fronteira seria, portanto, tão aceitável quanto a opção melhor quista para a maioria dos intelectuais brasileiros desde o século XIX: os imigrantes europeus. Contudo, a imigração não era a única saída. Melo e Silva também propunha um modelo escolar baseado nas escolas de ensino técnico voltados para a agricultura.

Entre as vantagens com que o governo poderia acenar, não só aos atuais, mas aos futuros habitantes daquela zona, figura a da criação de escolas 
profissionais e entre estas uma de ensino agrícola. Seria isso um prêmio aos brasileiros pobres que ali se fixam e que têm impossibilidade de dar qualquer profissão aos filhos. E são incalculáveis os resultados que advirão daí, do ponto de vista educativo e econômico" (MELO E SILVA, 2003, p. 195).

Seria, portanto, do Estado a tarefa de educar, de incutir ordem e progresso numa fronteira descontínua, irregular, flutuante. Essa era sobretudo uma missão nacinoal, pois não visava apenas o elemento guarani paraguaio, mas também a população brasileira pobre que habitava aquele lugar, e teria não apenas um fim educativo, mas também econômico Essa solução viria de encontro a outra, interligando sus propostas: as vias de comunicação com São Paulo. Abrir caminhos com a estrada de ferro, construir pontes e estradas, era integrar aquela nação, de veria ser projeto de primeira ordem: "Dentro dos limites das forças orçamentárias, sem esquecer escolas e caminhos, que ambas se completam e equivalem em resultados, nessa marcha em busca do progresso e do futuro" (MELO E SILVA, 2003, p. 140).

Modificar o meio transformaria o homem, assim como caldeá-lo com os imigrantes. Como podemos analisar, Melo e Silva bebeu das duas fontes, na medida em que postulava argumentos de um mendelismo positivado pela crença na melhora hereditária, e também ao propor reformas educacionais como forma de corrigir pelo exemplo e pelo ensino as raças guaranizadas e também do brasileiro pobre e esquecido pelo Estado, para que isso se propagasse nas próximas gerações, argumento em geral associado ao neolamarckismo.

Assim, as contradições apresentadas no texto, tanto em relação ao guarani paraguaio e o guarani brasileiro, quanto em relação ao caráter, espiritualidade, sexualidade, labor, entre outras características ora positivas e ora negativadas, nos parecem uma estratégia de escrita do texto. José Melo e Silva buscou demarcar sua escrita por sua experiência na fronteira filtrada por uma metodologia científica, baseada no cânone brasileiro, e utilizando-o como parâmetro para estabelecer verdades sobre aquela fronteira, sobre o nós e os outros. Nesta linha, as relações entre educação, cultura e sangue tornam-se cada vez mais frequentes, levando a um cenário ao mesmo tempo desolador e maravilhoso, que precisa de soluções para efetivar o progresso. Por isso, o autor mescla intenções de objetividade científica e neutralidade metodológica de análise com juízos de valor moral e caráter espiritual de seus objetos de pesquisa. Tal texto fez parte de um compêndio maior de autores e projetos que, naquele período, buscavam encontrar ou criar um índio aperfeiçoado para a civilização brasileira (GARFIELD, 2011, p. 62).

Este momento é o que Seth Garfield nomeou de uma relação entre a hegemonia e os descontentes, em que vários grupos de interesse atuaram na "pacificação" e expropriação de 
terras indígenas no oeste brasileiro (GARFIELD, 2011, p. 21). Para além da questão de terras e de violência física, os guaranis, também se tornaram objeto de estudo, subjugados pela crença no olhar neutro da ciência, que conduzem o leitor a ratificar as conclusões políticas do texto de Melo e Silva, que, afirmadas com autoridade, retomadas em outros tempos e espaços, naturalizam aquilo que não é natural, violando e forjando passados, identidades, regiões e suas fronteiras.

\section{Conclusões}

O texto de José de Melo e Silva não foi o único a emitir pareceres acerca do Oeste brasileiro. Contudo, a escolha desta fonte para trabalhar o tema da violência aos indígenas recai também sobre os usos posteriores da obra, aqui pouco abordados. A continuidade ou não destes narrativas que demarcam lugares para as populações indígenas da fronteira Brasil/Paraguai depende, em grande parte, da reafirmação dos próprios projetos de existência regional que fazem uso de tais discursos para legitimar modelos de sociedade atuais.

Esse texto de Melo e Silva foi republicado em 2003, pelo Instituto Histórico e Geográfico do Mato Grosso do Sul, como uma ode à memória daquele Estado. Contudo, entendemos que ao narrar e criar aquelas pessoas por meio de seu texto, Melo e Silva projetou sobre eles uma história e um destino: de não pertencer, a não ser que fossem modificados. Ao mesmo tempo, projetou o Brasil como potência sul-americana que se projeto sobre os países vizinhos com poder. Sendo assim, Fronteiras Guaranis (1939) deve ser problematizado, e não apenas comemorado. Entende-se que na medida em que textos participam da construção de regiões e delegam identidades, imprimem em suas páginas fronteiras simbólicas e lugares de poder. Esses discursos passam por processos de redescoberta reatualização, que buscam continuidades no passado e muitas vezes imprimem regiões retroativas (FIUZA, 2017, p. 43).

Neste caso, a região Mato Grosso do Sul, baseada na propriedade de terras, com uso agropecuário e no ecoturismo, que continuam a estabelecer um lugar secundário e exótico aos indígenas fronteiriços, abaixo na hierarquia de poderes sociais. É importante que estas ideias sejam mapeadas no jogo presente-passado-presente, de modo afinal, quando se trata de regiões, é preciso suspeitar das continuidades (ALBUQUERQUE JR, 2011, p. 35).

Essa pesquisa abriu um leque de possibilidades. A circulação da obra de José de Melo e Silva foi analisada apenas no Brasil, sem consultar fontes paraguaias, interpretando tanto a presença quanto a ausência como evidências da história. Também é importante que sejam feitas pesquisas sobre as diferentes narrativas de povos guaranis nas fronteiras internacionais, e entende-las como relações de poder construídas sobre a partir de textos, que não relatam 
verdades mas (re)criam e (re)posicionam os indígenas na sociedade. Inclusive, entende-se ser necessário propor estudos com este viés acerca do contexto de Moisés Bertoni, que aqui é apresentado por um interlocutor nacionalista brasileiro, que também desvela uma relação de poder que pode ser questionada.

\section{Referências}

ALBUQUERQUE JR, Durval Muñiz. A Invenção do Nordeste e outra artes. São Paulo: Cortez, 2011.

CALONGA, Dantielly. A Marcha para Oeste e os intelectuais em Mato Grosso: política e identidade. Revista Espaço Acadêmico. Maringá, n. 168, p. 126-132, Mai. 2015.

CHARTIER, Roger. A Mão do Autor e a Mente do Editor. Assis: Editora UNESP, 2014.

DÁVILA, Jerry. Diploma de Brancura: política racial e social no Brasil (1917-1945). São Paulo: Editora Unesp, 2005.

FOUCAULT, Michel. A Ordem do Discurso. São Paulo: Edições Loyola, 2014.

O que é um autor? In: Ditos e Escritos: Estética - literatura e pintura, música e cinema (vol. III). Rio de Janeiro: Forense Universitária, 2001. p. 264-298.

FIUZA, Wagner Henrique Neres. Do Sul de Mato Grosso ao Mato Grosso do Sul: região e historiografia em torno da obra de José de Melo e Silva. Dissertação [Mestrado em História]. Irati: UNICENTRO, 2017.

FREITAG, Liliane. Extremo-Oeste Paranaense: História Territorial, Região, Identidade e (Re)Ocupação. Tese [Doutorado em História]. Franca: UNESP, 2007.

GARFIELD, Seth. A Luta Indígena no Coração do Brasil. Política Indigenista, a Marcha para o Oeste e os Índios Xavante (1937-1988). São Paulo: Editora Unesp, 2011.

SILVA, José de Melo e. Fronteiras Guaranis. 2 ed. Campo Grande: IHGMS, 2003.

STEPHAN, Nancy. A Eugenia no Brasil - 1917 a 1940. In: HOCHMAN, Gilberto; ARMUS, Diego (orgs). Cuidar, Controlar, Curar: ensaios históricos sobre saúde e doença na América Latina e Caribe. Rio: Editora Fiocruz, 2004

VELlOSO, Mônica Pimenta. Os intelectuais e a política cultural do Estado Novo. Rio de Janeiro: FGV - Centro de Pesquisa e Documentação de História Contemporânea do Brasil, CPDOC, 1987. 